\title{
Congenital Chylothorax and Hydrops Fetalis in Newborn: A Case Report
} Dr. Mahmoud M. Osman*, Dr. Mohamed Ali Tagin, Dr. Mohammed Saleh Alissa, Dr. Suzan Abdel-Hamid, Dr. Mohamed Salah Shoeib

Neonatal Intensive Care Unit, Al Yamamah Hospital, Riyadh, Saudi Arabia

DOI: $\underline{10.36347 / \text { simcr.2020.v08i02.019 }}$

| Received: 06.02.2020 | Accepted: 14.02.2020 | Published: 16.02.2020

*Corresponding author: Dr. Mahmoud Mohamed Osman

Abstract

Case Report

Congenital chylothorax is the accumulation of chyle (lymphatic fluid) within the pleural space in fetus. Chyle is a sterile fluid that appears straw or milky colored depending on the infant's feeding status. Herein we present a 35 weeks gestational age female infant antenatally diagnosed to have hydrops fetalis with bilateral chylothorax. Fetal interventions were applied. Her management was conservative approach and her outcome was favorable.

Keywords: Chylothorax, Congenital, Hydrops Fetalis, Pleural Effusion, Fetal Interventions.

Copyright @ 2020: This is an open-access article distributed under the terms of the Creative Commons Attribution license which permits unrestricted use, distribution, and reproduction in any medium for non-commercial use (NonCommercial, or CC-BY-NC) provided the original author and source are credited.

\section{INTRODUCTION}

Chylothorax is abnormal accumulation of lymphatic fluid in the pleural space secondary to leakage from thoracic duct or one of its tributaries. It is a relatively rare condition in newborns, and may be classified as congenital or acquired [1]. The etiology of congenital chylothorax is not clear, but it is thought to be related to congenital malformations of the lymphatic system [2]. Chyle is composed of fats, immune cells and proteins; chylothorax is associated with respiratory, metabolic, nutritional and immunological morbidities. When chylothorax is associated with hydrops, it becomes a potentially life-threatening condition [3]. Chylothorax treatment includes pleural fluid aspiration and chest tube insertion for diagnostic purposes and to relieve respiratory distress. Nutritional support involves medium chain triglycerides (MCT) formula that is absorbed directly to portal circulation and bypasses intestinal lymphatics. Some authors recommend TPN to provide complete gut rest to minimize lymph production and to allow healing of the thoracic duct [4].

\section{Case Report}

A 36 years old primigravida mother with blood group $\mathrm{O}$ positive; diagnosed at 15 weeks gestation to have a fetus with hydrops fetalis, bilateral pleural effusions and ascites. Cardiocentesis was done and her karyotype was $(46, \mathrm{XX})$ normal female. Repeated aspirations of the pleural and ascitic fluids were done; and analysis suggested chylothorax. At 35 weeks gestation an emergency cesarean section was carried out. The product was a baby girl with birth weight
$2.800 \mathrm{~kg}\left(75^{\text {th }}\right.$ centile), length $44 \mathrm{~cm}$ (below $25^{\text {th }}$ centile) and head circumference $31 \mathrm{~cm}\left(25^{\text {th }}\right.$ centile $)$. APGAR scores were seven and eight at one and five minutes respectively. The baby developed severe respiratory distress and mechanical ventilation was instituted. Initial physical examination revealed no dysmorphic features; but distended abdomen with redundant abdominal wall. Chest and abdomen radiography (Figure-1) and ultrasongraphy (Figure-2) showed bilateral pleural effusions more in the right side and massive ascites.

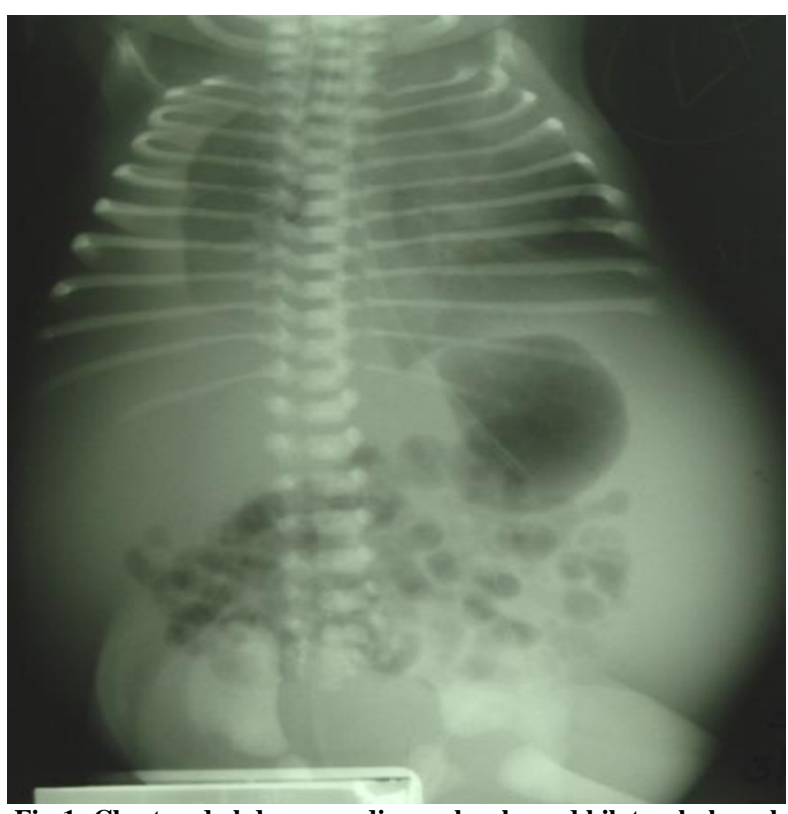

Fig-1: Chest and abdomen radiography showed bilateral pleural effusions more in the right side and massive ascites 


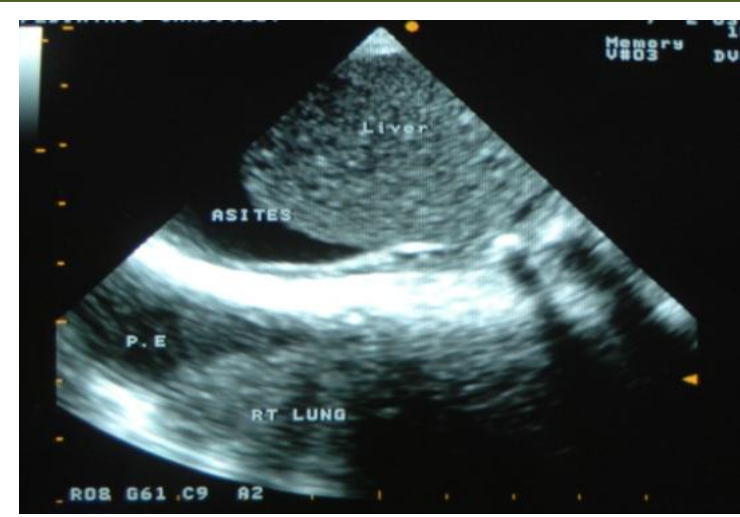

Fig-2: Chest and abdomen U/S showed large right pleural effusion and ascites

Echocardiography revealed normal heart anatomy, mild pulmonary hypertension and no pericardial effusion. Brain ultrasound was normal. Her initial complete blood count was normal, blood group was $\mathrm{O}$ positive, and DCT (Direct Coomb's Test) was negative. Screening for Toxoplasma, Hepatitis, Rubella, Cytomegalovirus, Syphilis, and Herpes Simplex were negative. The patient was kept NPO and total parenteral nutrition was commenced. Serum protein and albumin were low so replaced by fresh frozen plasma and human albumin $20 \%$. Inotropic support was needed for the first 5 days. Diagnostic thoracentesis extracted $20 \mathrm{ml}$ from the right side for cytology, biochemistry, and culture tests. It revealed 200 white cells $/ \mu \mathrm{L}$, no red blood cells, protein $0.746 \mathrm{~g} / \mathrm{dl}$ and glucose $5 \mathrm{mmol} / \mathrm{l}$. Culture was sterile. Paracentesis was done and $80 \mathrm{ml}$ fluid collected and sent for analysis that showed no white cells, red cells $48,000 / \mu \mathrm{L}$, no organisms and culture was sterile. The baby was running smooth course which tempted us to challenge her on the fifth day with OGT regular milk formula and the amount was increased gradually up to $30 \mathrm{ml}$ every 3 hours. On the seventh day repeated ultrasonography showed minimal bilateral pleural effusion, and mild to moderate ascites which did not need any intervention. On the thirteenth day, chest radiography showed massive accumulation of the right pleural fluid. Thoracentesis was done and showed milky fluid confirmed to be chyle by analysis (white cells $40,400 / \mu \mathrm{L}$ with $85 \%$ lymphocytes, red cells 20,000 $/ \mu \mathrm{L}$, total protein $1.436 \mathrm{~g} / \mathrm{dl}$ and glucose $5.7 \mathrm{mmol} / \mathrm{l}$. The culture was sterile. The baby was kept NPO and right chest tube drain was inserted and kept under water seal. Repeated pleural fluid analysis confirmed it to be chyle (white cells $24,000 / \mu \mathrm{L}$ with $95 \%$ lymphocytes, red cells $22,000 / \mu \mathrm{L}$, glucose $5.5 \mathrm{mmol} / \mathrm{l}$, cholesterol $1.7 \mathrm{mmol} / \mathrm{l}$, triglycerides $2.67 \mathrm{mmol} / \mathrm{l})$. On day $19^{\text {th }}$ the baby started on a special formula containing medium chain triglycerides. The amount of chyle collected regressed day after day. The baby's general condition improved, edema and ascites subsided and the chest tube removed on day $20^{\text {th }}$. Chest radiography revealed no pleural fluid, hypoplastic/collapsed right lung with mediastinum shift and hyperinflation of the left lung. These results were confirmed by chest computed tomography (Figure 3). Abdominal Computed tomography showed no masses or fluid collection. Several attempts to extubate the baby failed due to severe respiratory distress and $\mathrm{CO}_{2}$ retention. Fortunately at the age of 41 days and after short course of dexamethasone the baby successfully extubated. Regular milk formula was restarted with no reaccumulation of chyle. She gained weight nicely and discharged on age of 77 days with a body weight 3.250 $\mathrm{kg}$. She had regular follow-up in the outpatient clinic. She was doing fine with normal development at age of 11 months; but she still had some retractions with pectus excavatum deformity. Repeated chest radiography showed better inflation in right lung (Figure 4).

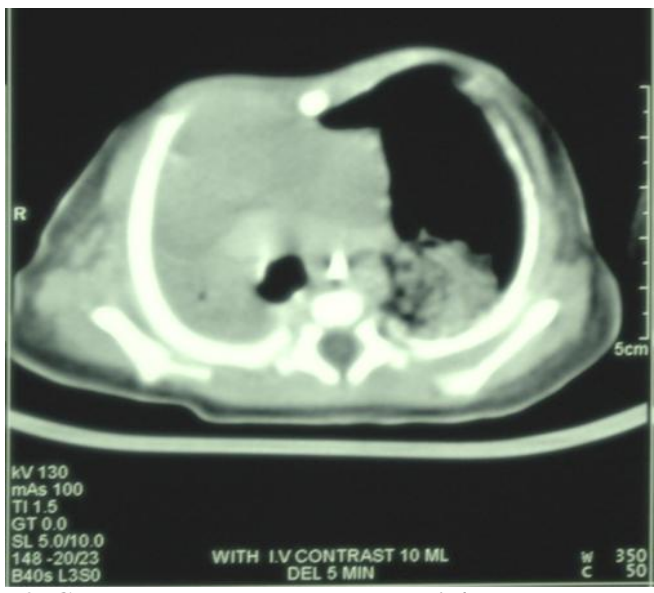

Fig-3: CT-scan chest showed hypoplastic/collapsed Rt. lung, shifted mediastinum and hyperinflated left lung

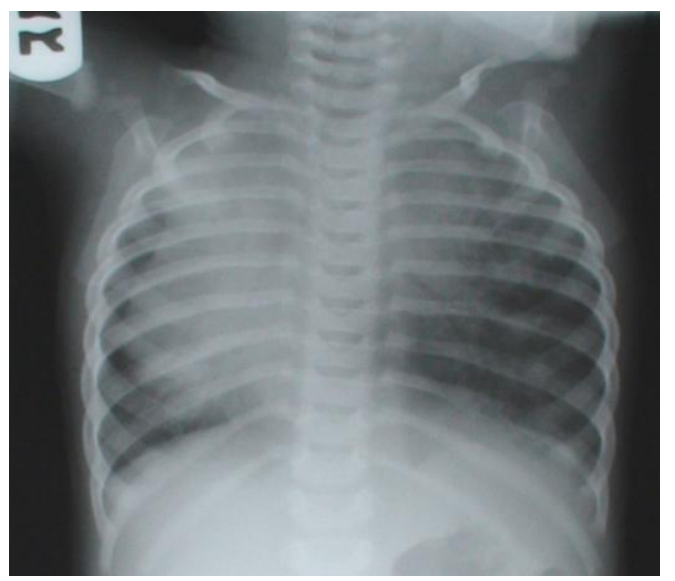

Fig-4: Chest radiography at 11 months showed better inflation in Right Lung

\section{DiscuSSION}

Chylothorax or chylous pleural effusion refers to presence of Chyle (lymphatic fluid) in the pleural space. Chyle is a milky fluid characterized by $\mathrm{T}$ lymphocyte predominance (90\%), high triglyceride levels $(>110 \mathrm{mg} / \mathrm{dl})$, protein content equal to that of plasma and total cell count more than 1000 cells/ $\mu \mathrm{L}$ [5]. Chylothorax is an uncommon cause of respiratory distress in newborns and is a potentially life threatening disorder. It can lead to serious metabolic, immunological, and nutritional complications [6]. 
In idiopathic congenital chylothorax, neonates have a weak thoracic duct or lymphatic anomalies; so any increase in venous pressure may cause a leak. In the majority of cases the exact etiology is unknown in spite of relevant investigations [7]. Congenital Chylothorax can be an isolated or associated with genetic conditions such as Trisomy 21, Turner and Noonan syndromes. Chylothorax can occur secondary to laceration of the thoracic duct, from sudden hyperextension of the neck, stretching of the chest wall during delivery, and after surgeries involving structures in the neck and thorax [8].

The strategy of treatment is the same regardless of the etiology. The first step is thoracentesis for initial drainage and diagnostic purposes. Chest tube drainage is indicated if the effusion causes respiratory distress or the accumulation recurs [9]. Nutritional support is aimed at providing adequate caloric intake while minimizing the chyle flow in the thoracic duct while waiting for healing. This is usually achieved by feeding with a formula high in medium chain triglycerides (MCT), which bypasses the intestinal lymphatic system and is absorbed directly to the portal vein. Close monitoring of reaccumulation of pleural effusion, is achieved either by chest tube drainage or ultrasound [10]. It has been suggested that drainage can be used as a guide for clinical improvement or failure; pleural drainage of $<10 \mathrm{~mL} / \mathrm{kg}$ per day is considered an improvement, but $>10 \mathrm{~mL} / \mathrm{kg}$ per day is considered a failure after 4 weeks of nonsurgical management [11]. Surgery should be considered when medical management fails; thoracic duct ligation, pleurodesis and pleura-peritoneal shunts are the most utilized procedures [12]. Infants whose chylothoraces are diagnosed $<34$ weeks of gestation and who receive prenatal therapy experience better perinatal and postnatal outcomes. Therapeutic measures during prenatal period include maternal dietary modification, repeated thoracentesis, thoraco-amniotic shunting, and pleurodesis [13]. Octreotide is a long-acting synthetic somatostatin analogue; it is an effective conservative therapeutic modality for congenital chylothorax. Though mechanism of action has not been fully elucidated, it could be vasoconstriction of splanchnic vasculature leading to reducing intestinal secretions and lymphatic flow [14].

\section{CONCLUSION}

Congenital chylothorax is a very rare cause of respiratory distress in neonates. Diagnosis of this condition based on clinical, radiological, and pleural fluid findings. Conservative therapy should be tried first before a surgical procedure might be considered. Octreotide is an emerging agent in conservative therapy. Reporting such case can be assistance to pediatricians for managing this disease and reducing the resultant morbidity and mortality.

\section{Funding: None \\ Conflict of Interest: None}

\section{REFRENCES}

1. Dehghan K. Idiopathic Chylothorax in a Term Neonate and Successful Treatment with Octreotide and Medium Chain Triglyceride Enriched Formula: A Case Report. International Journal Pediatr, 2019; 7(6):9535-40.

2. Ambrosio B, Fonseca J, Ferreira AP. Congenital chylothorax - a case report. Acta Obstet Ginecol Port, 2018; 12(2): 150-152

3. Utture A, Kodur V, Mondkar J. Chemical Pleurodesis with Oxytetracycline in Congenital Chylothorax. Indian Pediatrics. 2016; (53):11051106

4. Ahmed M, Alshafei AH, Khan A, Gouda A. Neonatal bilateral chylothorax treated by octreotide. Hamdan Med Journal. 2018; 11:34-6.

5. Skouras V, Kalomenidis L. Chylothorax: diagnostic approach, Wolters Kluwer Health, Lippincott Williams \&Wilkins, 2010; 16: 387-93.

6. Mirzarahimi M, Hosseini Khotbesara M, Hosseini Khotbesara M, Bagheri A. A newborn with a congenital chylothorax. Iranian Journal of Neonatology IJN. 2014;5(2):40-2.

7. Rawat JD, Singh S, Singh G, Chaubey D. Congenital idiopathic chylothorax: A very rare case. Journal Clin Neonatol, 2017; 6:205-7.

8. Krishnamurthy MB, Malhotra A. Congenital chylothorax: current perspectives and trends. Research and Reports in Neonatology. 2017;7:5363.

9. Dehghan K, Soto-Martinez M, Massie J. Chylothorax: diagnosis and management in children. Paediatr Respir Rev 2009; 10: 199-207.

10. Foo NH, Hwang YS, Lin CC, Tsai WH, Congenital chylothorax in a late preterm infant and successful treatment with octreotide, Journal Pediatrics and Neonatology, 2011; 52:297-301.

11. Dori L, Smaropoulos E, Tagarakis G, Foroulis CN, Zarogoulidis P, Huang H, Chong B, HohenforstSchmidt W, Tsikopoulos G. Successful treatment of familial congenital chylothorax by ligation of the thoracic duct: A case report. Respiratory medicine case reports. 2017 Jan 1;21:66-8.

12. Ameur SB. Congenital Chylothorax: Management and Long-term Outcome A Case Report and Literature Review. J Clin Case Rep. 2015;5(668):2.

13. Lee CJ, Tsao PN, Chen CY, Hsieh WS, Liou JY, Chou HC. Prenatal therapy improves the survival of premature infants with congenital chylothorax. Pediatr Neonatol. 2016; 57(2):127-132.

14. Bulut O, Gul D, Sevuk S, Mungan I, Buyukkayhan D. Treatment of chylothorax developed after congenital heart disease surgery: a case report. North Clin Istanbul, 2015;2(3):227-230. 